\title{
Persistence of soil organic matter as an ecosystem property
}

Michael W. I. Schmidt ${ }^{1 *}$, Margaret S. Torn ${ }^{2,3 *}$, Samuel Abiven ${ }^{1}$, Thorsten Dittmar ${ }^{4,5}$, Georg Guggenberger ${ }^{6}$, Ivan A. Janssens ${ }^{7}$, Markus Kleber ${ }^{8}$, Ingrid Kögel-Knabner ${ }^{9}$, Johannes Lehmann ${ }^{10}$, David A. C. Manning ${ }^{11}$, Paolo Nannipieri ${ }^{12}$, Daniel P. Rasse ${ }^{13}$, Steve Weiner ${ }^{14}$ \& Susan E. Trumbore ${ }^{15}$

Globally, soil organic matter (SOM) contains more than three times as much carbon as either the atmosphere or terrestrial vegetation. Yet it remains largely unknown why some SOM persists for millennia whereas other SOM decomposes readily-and this limits our ability to predict how soils will respond to climate change. Recent analytical and experimental advances have demonstrated that molecular structure alone does not control SOM stability: in fact, environmental and biological controls predominate. Here we propose ways to include this understanding in a new generation of experiments and soil carbon models, thereby improving predictions of the SOM response to global warming.

Understanding soil biogeochemistry is essential to the stewardship of ecosystem services provided by soils, such as soil fertility (for food, fibre and fuel production), water quality, resistance to erosion and climate mitigation through reduced feedbacks to climate change. Soils store at least three times as much carbon (in SOM) as is found in either the atmosphere or in living plants ${ }^{1}$. This major pool of organic carbon is sensitive to changes in climate or local environment, but how and on what timescale will it respond to such changes? The feedbacks between soil organic carbon and climate are not fully understood, so we are not fully able to answer these question $s^{2-7}$, but we can explore them using numerical models of soil-organic-carbon cycling. We can not only simulate feedbacks between climate change and ecosystems, but also evaluate management options and analyse carbon sequestration and biofuel strategies. These models, however, rest on some assumptions that have been challenged and even disproved by recent research arising from new isotopic, spectroscopic and molecularmarker techniques and long-term field experiments.

Here we describe how recent evidence has led to a framework for understanding SOM cycling, and we highlight new approaches that could lead us to a new generation of soil carbon models, which could better reflect observations and inform predictions and policies.

\section{The conundrum of SOM}

About a decade ago, a fundamental conundrum was articulated ${ }^{8}$ : why, when organic matter is thermodynamically unstable, does it persist in soils, sometimes for thousands of years? Recent advances in physics, material sciences, genomics and computation have enabled a new generation of research on this topic. This in turn has led to a new view of soil-organic-carbon dynamics-that organic matter persists not because of the intrinsic properties of the organic matter itself, but because of physicochemical and biological influences from the surrounding environment that reduce the probability (and therefore rate) of decomposition, thereby allowing the organic matter to persist. In other words, the persistence of soil organic carbon is primarily not a molecular property, but an ecosystem property.

This emerging view has not been fully implemented in global models or research design, for a variety of reasons. First, the knowledge gathered in the past decade has often been published in outlets of traditionally separated disciplines. As a result, confusion has arisen because these different disciplines can use the same vocabulary to mean different things, or vice versa. For example, 'decomposition rates' may mean the rate of mass loss of fresh litter, the production rate of $\mathrm{CO}_{2}$ in a laboratory incubation, or the rate inferred from input and loss of an isotopic tracer present in plant inputs to soil ${ }^{9,10}$. Second, the complexity of the soil system is difficult to incorporate into one conceptual model or to translate into a tractable yet accurate numerical model. Soil is a realm in which solid, liquid, gas and biology all interact, and the scale of spatial structures spans many orders of magnitude (from nanometre minerals to football-sized soil clods). Indeed, the spatial heterogeneity of biota, environmental conditions and organic matter may have a dominant influence on carbon turnover and trace gas production in soils. Last, the new knowledge remains more qualitative than quantitative. In many cases, it tells us what is important and suggests new model structures, but not how to parameterize them.

\section{Recent insights into carbon cycling}

Since pioneering work in the $1980 \mathrm{~s}^{11}$, new insights gathered across disciplines (ranging from soil science to marine science, microbiology, material science and archaeology) have challenged several foundational principles of soil biogeochemistry and ecosystem models; in particular, the perceived importance of the 'recalcitrance' of the input biomass (the idea that molecular structure alone can create stable organic matter) and of humic substances (biotic or abiotic condensation products). New observations show these to be only marginally 


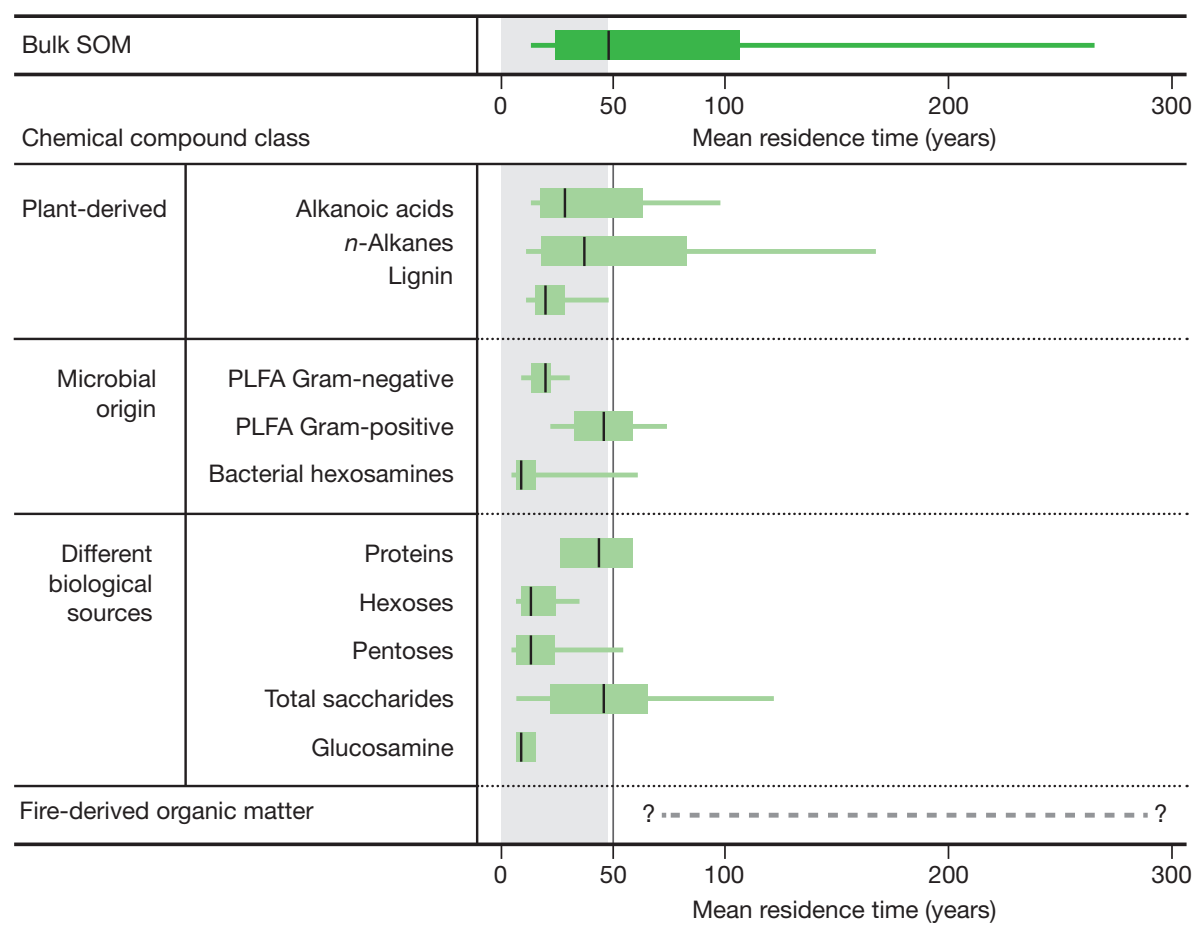

Figure $1 \mid$ Molecular structure does not control long-term decomposition of soil organic matter (SOM). Certain plant-derived molecules (classically, longchain alkanoic acids, $n$-alkanes, lignin and other structural tissues) often persist longer than others while leaf or needle biomass is decaying. In mineral soil, however, these relatively persistent components appear to turn over faster than the bulk soil (top row), except for fire-derived organic matter (bottom row). Even components that appear chemically labile, including proteins and saccharides of plant and microbial origin ('Different biological sources'), instead seem to turn over (on average) at rates similar to those of bulk SOM, that is, on the order of years or even decades. Thus, over time, the importance of initial quality fades and the initially fast-cycling compounds are just as likely to

important for organic matter cycling ${ }^{12,13}$. Furthermore, loose use of the term 'recalcitrance' has significantly confused the discussion in the past.

We need to ensure that the conceptual framework that supports our understanding of soil carbon cycling is consistent with observations and has a mechanistic basis, as only then can we start to make the necessary advances in terrestrial ecology and improve our ability to predict soil responses to changes in climate, vegetation or management. Here we articulate key insights into soil carbon cycling synthesized from research of the past decade, and describe the research challenges they pose for the coming decade.

\section{Molecular structure and decomposition}

The initial decomposition rate of plant residues correlates broadly with indices of their bulk chemical composition, such as the nitrogen content or the fraction of plant residue that cannot be solubilized by strong acid treatments (often operationally defined as 'lignin') ${ }^{14}$. Accordingly, the molecular structure of biomass and organic material has long been thought to determine long-term decomposition rates in the mineral soil. However, using compound-specific isotopic analysis, molecules predicted to persist in soils (such as lignins or plant lipids) have been shown to turn over more rapidly than the bulk of the organic matter (Fig. 1) ${ }^{12,15-17}$. Furthermore, other potentially labile compounds, such as sugars, can persist not for weeks but for decades. We therefore cannot extrapolate the initial stages of litter decomposition to explain the persistence of organic compounds in soils for centuries to millennia-other mechanisms protect against decomposition. Perhaps certain compounds require co-metabolism with another (missing) compound, or microenvironmental conditions persist as the slow ${ }^{12,15}$. This figure compiles data from surface horizons of 20 long-term field experiments (up to 23 years) in temperate climate, using ${ }^{13} \mathrm{C}$ labelling to trace the residence time of bulk SOM and of individual molecular compounds. The variation in turnover time is also seen in the compounds of microbial origin analysed for ${ }^{13} \mathrm{C}$ content, phospholipid fatty acids (PLFA) produced by Gram-negative and Gram-positive bateria and amino sugars (hexosamines). Redrawn from ref. 15 (with permission); for clarity, we have excluded outliers, and we have added the tentative data on fire-derived organic matter. Data points: thin horizontal lines, 10th and 90th percentiles; box, 25th and 75th percentiles; central vertical line, median.

restrict the access (or activity) of decomposer enzymes (for example, hydrophobicity, soil acidity, or sorption to surfaces ${ }^{18}$ ).

\section{Soil humic substances}

The prevalence of humic substances in soil has been assumed for decades $^{19}$. Previous generations of soil chemists relied on alkali and acid extraction methods ${ }^{20}$ and observations of the extracted (or residual) functional-group chemistry to describe the presence of operationally defined 'humic and fulvic acids' and 'humin'. Humin was thought to comprise large, complex macromolecules that were the largest and most stable SOM fraction. However, we now understand that these components represent only a small fraction of total organic matter ${ }^{13,21-23}$ : direct, in situ observations, rather than verifying the existence of these large, complex molecules, in fact find smaller, simpler molecular structures, as visualized in Fig. 2 (refs 13, 22, 23). Some of what is extracted as humic acids may be fire-derived ${ }^{24,25}$, although these compounds are rare in soil without substantial firederived organic matter. In any case, there is not enough evidence to support the hypothesis that the de novo formation of humic polymers is quantitatively relevant for humus formation in soils.

\section{Fire-derived organic matter}

Fire-derived organic matter (also called char, black carbon or pyrolysed carbon) is found in many soils, sediments and water bodies, and can comprise up to $40 \%$ of total SOM in grasslands and boreal forests $^{26}$. It is not inert, but its decomposition pathways remain a mystery. Fire-derived carbon was suspected to be more stable in soil than other organic matter because of its fused aromatic ring structures and the old radiocarbon ages of fire residues isolated from soil ${ }^{27}$. However, 


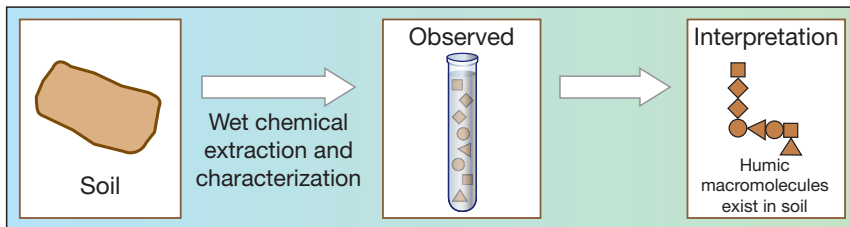

b Emerging understanding

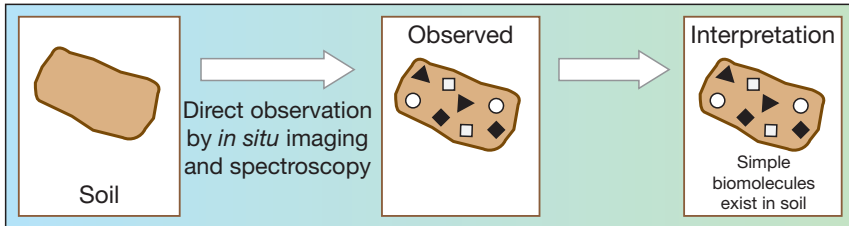

Figure 2 In soil, the existence of humic substances has not been verified by direct measurements. a, Based on chemical analysis of the extracted materials (Observed), the de novo formation of humic polymers (Interpretation) was postulated to be an important source of recalcitrant SOM. b, Direct highresolution in situ observations with non-destructive techniques (Observations) have been able to explain the functional group chemistry of the extracted humic substances as relatively simple biomolecules (Interpretation), without the need to invoke the presence of unexplainable macromolecules ${ }^{100}$. Moreover, the chemical mixture of SOM is spatially distinct on a nanometre scale, and the aromatic/carboxylate-rich compounds characteristic of the bulk extracted humic substances have not been found in situ even when looking at the submicrometre scale (using near-edge X-ray fine structure spectroscopy combined with scanning transmission X-ray microscopy $)^{22}$.

fire-derived carbon does undergo oxidation and transport, as we now know from archaeological settings ${ }^{28}$, soils ${ }^{29,30}$, and from breakdown products in river $^{31}$ and ocean water ${ }^{32,33}$. In a field experiment, firederived residues were even observed to decompose faster than the remaining bulk organic matter, with $25 \%$ lost over 100 years (ref. 29). Spectroscopic characterization shows that combustion temperature affects the degree of aromaticity and the size of aromatic sheets, which in turn determine short-term mineralization rates ${ }^{22,34-36}$. To reconcile the observations of decomposability with the old radiocarbon ages of fire-derived carbon deposits ${ }^{37,38}$, it has been suggested that physical protection and interactions with soil minerals play a significant part in black-carbon stability over long periods of time ${ }^{39}$.

\section{Influence of roots}

Root-derived carbon is retained in soils much more efficiently than are above-ground inputs of leaves and needles ${ }^{40-42}$. Isotopic analyses and comparisons of root and shoot biomarkers confirm the dominance of root-derived molecular structures in soil ${ }^{43}$ and of root-derived carbon in soil microorganisms ${ }^{44}$. Preferential retention of root-derived carbon has been observed in temperate forests ${ }^{45,46}$, for example, where belowground inputs, including fungal mycelia, make up a bigger fraction of new carbon in SOM than do leaf litter inputs ${ }^{44,47}$. In addition to many above-ground inputs being mineralized in the litter layer, root and mycorrhizal inputs have more opportunity for physico-chemical interactions with soil particles ${ }^{40}$. At the same time, fresh root inputs may 'prime' microbial activity, leading to faster decomposition of older organic matter ${ }^{48,49}$ as well as changing community composition ${ }^{50}$. Carbon allocation by plants thus plays an important part in soil carbon dynamics, but it is not known how future changes in plant allocation will affect soil carbon stocks ${ }^{51}$.

\section{Physical disconnection}

The soil volume occupied by micro-organisms is considerably less than 1\%: this occupied volume is distributed heterogeneously in small-scale habitats, connected by water-saturated or unsaturated pore space ${ }^{18}$. The availability of spatially and temporally diverse habitats probably gives rise to the biodiversity that we see in soil, but this fragmentation of habitat may restrict carbon turnover. At present, we are far from being able to quantify the complex processes of soil structure development and fragmentation, which have different space scales and timescales depending on soil type, texture and management ${ }^{10}$. The physical disconnection between decomposer and organic matter is likely to be one reason for persistence of deep SOM. The specific pedological processes operating in a given soil type that influence the distribution of organisms and substrates, such as bioturbation and formation of preferential flow paths, need to be taken into account to understand and quantify subsoil carbon dynamics, and thus its vulnerability to decomposition ${ }^{52}$.

\section{Deep soil carbon}

There is a lot more deep soil carbon than we once thought, and the underlying processes inhibiting its turnover are still largely unknown. Despite their low carbon concentrations, subsoil horizons contribute to more than half of the global soil carbon stocks ${ }^{53}$. In fact, the response of deep soils to land-use change can equal that from the top $30 \mathrm{~cm}$ of soil, even though typically only the shallow depths are explicitly represented in models ${ }^{54}$. Inputs of carbon to the subsoil include dissolved organic matter, root products, and transported particulates from the surface ${ }^{55}$, but the relative importance of different sources is not known ${ }^{56}$. Based on depth trends of elemental composition (decreasing $\mathrm{C} / \mathrm{N}$ ratio), isotopic composition (increasing $\delta^{13} \mathrm{C}$ values) and individual organic compounds, microbial products make up more organic matter in subsoil horizons than do plant compounds ${ }^{57}$.

Organic matter in subsoil horizons is characterized by very long turnover times that increase with depth-radiocarbon ages of 1,000 to $>10,000$ years are common-but the reasons for this are not clear. Microbial activity may be reduced by suboptimal environmental conditions, nutrient limitation or energy scarcity, and organic matter may be less accessible because of its sparse density or association with reactive mineral surfaces. Microbial biomass decreases with soil depth $^{58}$, and community composition changes to reflect an increase in substrate specialization ${ }^{59}$. Recent studies suggest that energy limitation, or the converse-'priming' (see below) by root exudates or dissolved organic carbon-is an important factor in the subsurface ${ }^{48,49}$. Most studies concerning these factors, however, have been conducted in the laboratory, and their relevance in situ needs evaluation. If we do not understand these mechanisms of stabilization, we cannot predict the vulnerability of deep SOM to change.

\section{Thawing permafrost}

Permafrost soils store as much carbon (up to $1,672 \times 10^{15} \mathrm{~g}$; ref. 60) as was believed a decade ago to exist in all soils worldwide. During permafrost thaw, which is expected to become widespread owing to climate change, much of this SOM may be vulnerable to rapid mineralization $^{61}$ if it is primarily stabilized by freezing temperatures ${ }^{62}$. There is evidence that old carbon is mobilized following permafrost thaw $^{61,63}$, which indicates that organic matter previously locked in the permafrost is highly vulnerable. Moreover, the accelerated decomposition may increase nitrogen availability, which would amplify the direct effects of warming on microbial activity. Alleviation of nitrogen limitation in tundra experiments led to large and rapid carbon losses, including older carbon ${ }^{64,65}$. Over the very long term, however, formation of pedogenic reactive minerals in former permafrost soils may act to stabilize $\mathrm{SOM}^{66,67}$, and development of soil structure may lead to physical disconnection between organic matter and decomposers.

Despite some important recent research, surprisingly little is known about permafrost biogeochemistry and how the landscape would evolve with warming. Key questions surround the extent to which permafrost carbon is additionally stabilized by other processes beyond freezing, and the extent to which the active layer becomes saturated and anaerobic. The extent, rates and spatial variability of these processes are still largely unknown for permafrost soils, forming one of the major uncertainties in predicting climate-carbon feedbacks. 
Soil micro-organisms

Soil microbial diversity and activity can be characterized at molecular resolution, but the quantitative linkages to ecosystem function are uncertain $^{68,69}$. Soil micro-organisms influence SOM cycling not only via decomposition but also because microbial products are themselves important components of $\mathrm{SOM}^{70}$. As a result, environmental change can influence soil carbon cycling through changes in both metabolic activity and community structure. For example, microbial community shifts following nitrogen additions can have large effects on decomposition rates $^{50,51}$. New genetic and protein-based tools enable the quantification of soil microbiological abundance and functioning (for example, enzymatic gene expression), and can describe the microbial community composition with very high taxonomic resolution ${ }^{71}$. Nevertheless, the challenge remains of synthesizing this immense amount of detailed information ${ }^{72}$ and linking it to the rates and routes of SOM processing. To quantitatively relate microbial genomics to ecosystem function, we need a better understanding of microbial functional redundancy.

\section{Implications of these insights}

Taken together, these eight insights paint a broad picture of carbon cycling in soil that has implications for fundamental research, land management, and climate change prediction and mitigation (Fig. 3). They suggest that the molecular structure of plant inputs and organic matter has a secondary role in determining carbon residence times over decades to millennia, and that carbon stability instead mainly depends on its biotic and abiotic environment (it is an ecosystem property). Most soil carbon derives from below-ground inputs and is transformed, through oxidation by microorganisms, into the substances found in the soil. By moving on from the concept of recalcitrance and making better use of the breadth of relevant research, the emerging conceptual model of soil organic carbon cycling will help to unravel the mysteries surrounding the fate of plant- and fire-derived inputs and how their dynamics vary between sites and soil depths, and to understand feedbacks to climate change. We argue that the persistence of organic matter in soil is largely due to complex interactions between organic matter and its environment, such as the interdependence of compound chemistry, reactive mineral surfaces, climate, water availability, soil acidity, soil redox state and the presence of potential degraders in the immediate microenvironment. This does not mean that compound chemistry is not important for decomposition rates, just that its influence depends on environmental factors. Rather than describing organic matter by decay rate, pool, stability or level of 'recalcitrance'-as if these were properties of the compounds themselves-organic matter should be described by quantifiable environmental characteristics governing stabilization, such as solubility, molecular size and functionalization ${ }^{73}$.

\section{Soil response to global environmental change}

We now consider how these insights affect our use of numerical models. Such models are powerful tools for quantifying the complex interactions and feedbacks that will underpin soil responses to global change. A variety of models that include SOM dynamics have informed our response to environmental issues, including agricultural management, bioremediation and environmental water research ${ }^{74}$. Most model testing, however, has been at local-to-regional spatial scales, spanning seasons to decades (although the century-long Rothamsted experiments are a noteworthy exception). In the long term or at a global scale, mechanisms of SOM stabilization and destabilization that are not currently embedded in models have the potential to dominate soil carbon dynamics, making it vital that models are correct for the right reasons. Recent model intercomparisons reveal large differences among predictions of soil carbon stocks and fluxes in the next century, for example ${ }^{2}$, demonstrating how sensitive global carbon cycling is to assumptions about SOM decomposition dynamics.

Recent advances in our mechanistic understanding of soils, such as those described above, have not yet been incorporated into the widely used models of SOM cycling, which are all structured around the idea that a type, or pool, of organic material will have an intrinsic decay rate $^{75-78}$. These models rely on simple proxies-such as soil texture as
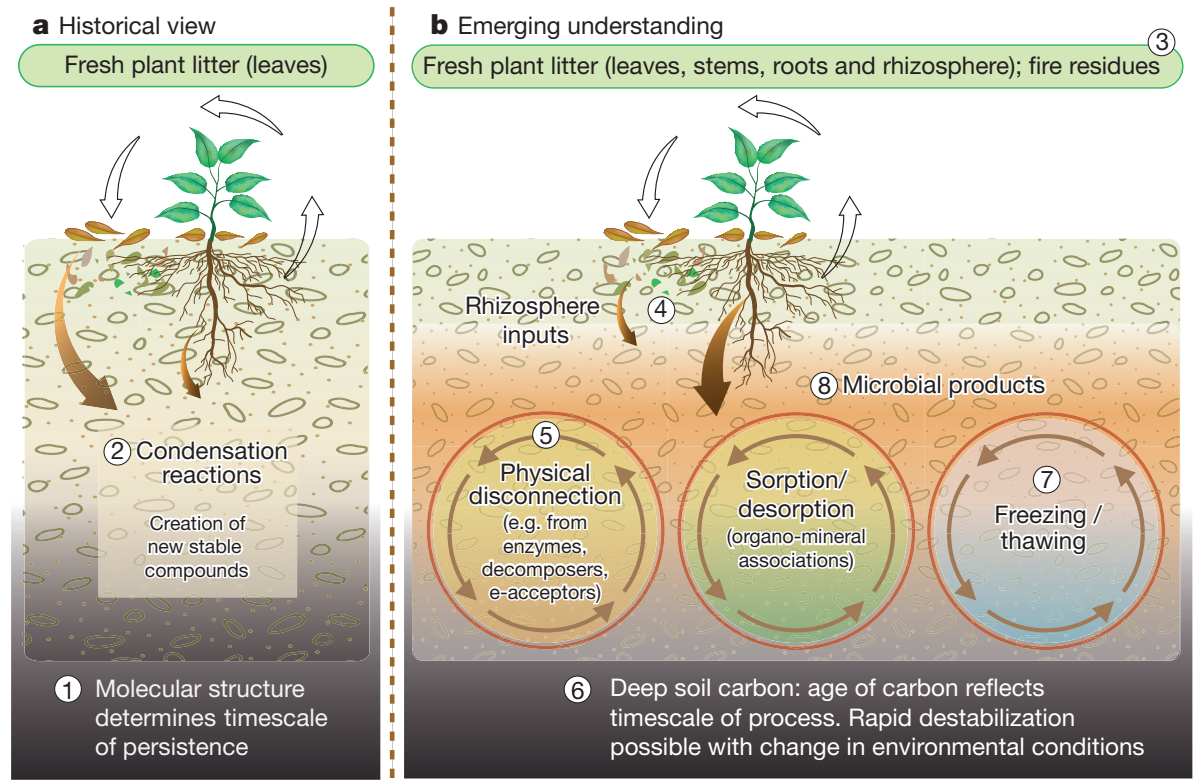

Figure $3 \mid$ A synopsis of all eight insights, contrasting historical and emerging views of soil carbon cycling. The historical view (a) has emphasized above-ground plant carbon inputs and organic matter in the top $30 \mathrm{~cm}$ of soil. Stable organic matter is seen to comprise mainly selectively preserved plant inputs and de novo synthesis products like humic substances, whose chemical complexity and composition render them nearly inert relative to microbial degradation. The emerging understanding $(\mathbf{b})$ is that the molecular structure of organic material does not necessarily determine its stability in soil (1; molecular structure). Rather, SOM cycling is governed by multiple processes (5) shaped by environmental conditions (such as physical heterogeneity). Plant roots and rhizosphere inputs (4; roots) make a large contribution to SOM, which is mainly partial degradation and microbial products and fire residues (3) rather than humic substances (2). The vulnerability of deep soil carbon (6; deep carbon) to microbial degradation (8; soil micro-organisms) in a changing environment, such as thawing permafrost (7; thawing permafrost) remains a key uncertainty. 
a surrogate for sorption and other organo-mineral interactions, and litter quality (such as lignin: $\mathrm{N}$ ratios or structural carbon groupings) as a means of partitioning plant inputs into pools of different turnover times-but in general these parameters are not consistent with the observations that are starting to emerge. Global models largely ignore deep mineral soils and are only now beginning to address the accumulation and loss of carbon in peatlands and permafrost ${ }^{79}$. Even more importantly, parameterizations based on litter chemistry may correlate well to initial rates of litter decomposition, but they have little relationship to the rates of decomposition for microbial residues or to organic matter sorbed to mineral surfaces or isolated in aggregates. Moreover, most models that make any allowances for microbial biomass treat it as a pool of carbon, rather than as an agent that affects the decomposition rate of SOM. The large disagreement among predictions of soil carbon fluxes in a warmer world highlights both the complexity of the many potential feedbacks to climate and the uncertainty that arises as a result ${ }^{2}$.

How does the perspective that SOM persistence is an ecosystem property inform our understanding of the response of decomposition to warming? The conventional assumption that older SOM is recalcitrant implies that this large carbon pool is highly temperature sensitive, because Arrhenius kinetics tells us that reactions with higher activation energies are more temperature-sensitive than those with low activation energies $^{80-82}$. Our ecosystem perspective suggests that the mechanisms governing the timing and magnitude of a response to a change in temperature are far more complex than this, as further physical, chemical and biological mechanisms controlling decomposition and stabilization would also be affected ${ }^{81,83,84}$. A recent incubation study of soils from a wide range of sites found that lower initial decomposition rates were associated with higher temperature sensitivity but not with any change in SOM quality indices ${ }^{85}$, suggesting that multiple stabilization mechanisms are temperature sensitive. Nevertheless, it is not yet possible to predict the integrated response of decomposition to changes in climate. In fact, we could use the ability to accurately predict temperature response as a guide to the degree of mechanistic representation that we need in our next generation of soil carbon models.

\section{Phyto-engineering}

Phyto-engineering to produce plant tissues high in chemical compounds resistant to rapid mineralization, such as plant lipids and lignin, has been suggested as a means to increase carbon sequestration $^{86}$. This strategy is called into question, however, if the molecular structure of plant compounds does not determine stability on the timescales necessary for significant carbon sequestration ${ }^{12,87}$. More generally, sequestration strategies based on adding recalcitrant material to soils, whether through plant selection for recalcitrant tissues or through biochar amendments, must be re-evaluated. Enhancing root carbon input to soils might be a more promising avenue, but it is not known what root properties influence rhizodeposition rates or stability $^{43}$, or the extent to which root inputs will stimulate (prime) decomposition of other SOM.

\section{Biochar}

Biochar (intentionally pyrolysed biomass) has gained much attention in recent years as a means to increase soil fertility and store carbon in soil for decades to centuries ${ }^{88}$. However, certain types of biochar can degrade relatively rapidly in some soils, probably depending on the conditions under which they were produced, which suggests that pyrolysis could be optimized to generate a more stable biochar. But as with natural fire residues, persistence over the long term may also be affected by interactions with minerals and by soil conditions (for microorganisms capable of char oxidation and for abiotic oxidation). Whether interactions of fire-derived carbon with soil minerals may be manipulated to enhance stability, and what the trade-offs might be with fertility benefits, are not known. Biochar is likely to be a useful part of sequestration-mitigation strategies, but more understanding of the variation in its decay rates is needed before we can develop simple (that is, policy-relevant) quantitative relationships between biochar additions and expected sequestration.

\section{Vulnerability of soil to degradation}

The vulnerability of SOM to degradation will depend on the nature of the disturbance as well as the stabilization and destabilization mechanisms at play in a given ecosystem. Hence, as with carbon stability, the vulnerability of soil stocks should not be assessed according to the classes of organic matter present, but rather according to the mechanisms through which organic matter is stabilized or made assimilable in that soil, and how these interacting physical, chemical and biological factors respond to chang $e^{5,6}$. Improved understanding of SOM destabilization is needed to enhance efforts to avoid soil degradation and accelerate recovery of degraded soils.

\section{The way forward}

Soils are now in the 'front line' of global environmental change-we need to be able to predict how they will respond to changing climate, vegetation, erosion and pollution so that we can better understand their role in the Earth system and ensure that they continue to provide for humanity ${ }^{89}$ and the natural world. The conceptual framework of soil carbon cycling presented here, that residence time is a property of the interactions between organic matter and the surrounding soil ecosystem, will help us get nearer to these goals ${ }^{7}$. This will require developed and entirely new lines of research and modelling, including: (1) applying a new generation of field experiments and analytical tools to study the processes driving SOM stabilization and destabilization; (2) developing a new generation of soil biogeochemistry models that represent the mechanisms driving soil response to global change; and (3) joining forces and connecting the disparate research communities that are studying, managing and predicting SOM cycling and terrestrial ecology.

\section{The next generation of experiments}

Although not a novel recommendation, we cannot overstate the need for long-term, manipulative experiments designed to test soil-based hypotheses. In some countries, long-term ecological observational networks already exist, but most were designed with vegetation or hydrology goals. Many are in danger of being discontinued. Although preserving these experiments is crucial, they may not be sufficient to untangle individual soil processes. In the near term, new disciplines and techniques could be applied to ongoing experiments, allowing the investigation of changes that occurred after decades of manipulation ${ }^{90}$. Focus is needed on long-term, controlled manipulations of entire soil profiles (that is, to a metre or more depth) to investigate distinct mechanisms in situ, and on observatories allowing quantification of budgets, such as large-scale lysimeters. In addition, research approaches are needed that combine manipulations with spatial gradients-and thus timescales - for variables and processes of interest. These new experiments should be designed to help determine the key soil functional traits for understanding and modelling thresholds in SOM storage and loss. Such traits, including soil depth, mineral charge density and $\mathrm{pH}$, vary spatially, but we suggest that their spatial distributions are ultimately predictable according to geologic setting, disturbance and management history, climate and ecosystem plant characteristics-in other words, the six state factors: climate, organisms, relief, parent material, time and human activity ${ }^{91}$. One of the major weaknesses of current models is the lack of representation of edaphic characteristics (that is, those physical and chemical features that are intrinsic to the soil) - and the fact that the major stabilization mechanisms will vary spatially with soil type and topographic positions.

\section{Tracing pathways, fluxes and biology}

When combined with manipulative experiments, new analytical techniques and instrumentation to study elements, isotopes and molecules 
in terrestrial ecosystems offer great potential for revealing the mechanisms underpinning soil carbon stability. Advances in physics, material sciences, genomics and computation continue to create new research opportunities. Because many, if not most, organic molecules in soils are of microbial origin, experiments are needed that identify the long-term drivers of microbial-cell and microbial-product decomposition, rather than focusing on the immediate fate of fresh plant material.

We propose extending the systems biology approach to the nonliving environment that surrounds organisms. Individual molecules could then be traced back from the soil into the cell via metabolic pathways and specific gene expressions. As with medicine, where structure-function relationships led to the development of genomics and proteomics, allowing illness to be treated before symptoms appear, we foresee that the integration of molecular, biological and physical information will provide soil science with a more mechanistic basis for predictions.

However, a major obstacle remains. The molecular complexity of SOM is extraordinary, and the metabolic products of higher plants and the diverse soil microbial community are mixed together in a three-dimensional inorganic soil matrix. An essential step to overcoming this obstacle is the identification of intact molecular structures in soils. In marine and freshwater sciences, ultrahigh-resolution (Fourier-transform ion cyclotron resonance) mass spectrometry has made it possible to identify tens of thousands of organic compounds in water and soil water, a major step towards implementing a systems biology approach in soils ${ }^{32}$. Ultrahigh-resolution mass spectrometry could be applied to soils by combining it with ionization techniques such as matrix-assisted laser desorption ionization.

For soils, any high-resolution molecular technique will have to be combined with imaging techniques in order to address spatial relationships and heterogeneity. Moreover, new spatial techniques will help uncover how microbial community structure, enzyme production and decomposition activity are influenced by environmental conditions and plant processes. For example, combining fluorescence in situ hybridization, which produces a spatial map of the microbial community, with secondary ion mass spectrometry imaging on a nanometre scale, can be a powerful way to link biota with processes at the submicrometre scale ${ }^{92,93}$.

Beyond imaging, new methods to trace particle and solute transport (for example, viral DNA labels) can help us to understand the processes linking deep and surface soils, and isotopic advances reveal both the movement and the chemical transformation of carbon in soil. The value of isotopically labelled inputs has been greatly amplified by new tools that allow precise measurements on small samples: it is now possible to follow labelled elements in the environment (for example, ${ }^{14} \mathrm{C}$ ), and to 'fingerprint' specific plant compounds and microbial products in soil, and therefore to determine how decomposition pathways and substrate ages interact. For measuring carbon isotopic values in gas and water fluxes, we no longer need to rely on weekly measurements, which carry the danger of missing episodic but crucial events. Quantum cascade and cavity ring-down laser spectroscopy allow high-frequency observations of the molecular and isotopic composition of soil gas, efflux and water.

\section{Integrative computational databases}

Advanced analytical methods are generating an ever-increasing amount of data on SOM. Soil DNA databases are currently being developed nationally ${ }^{94}$ and internationally (for example, soil microbial genomics libraries). In parallel, data-fusion-type techniques are now being applied to the large data sets generated by microbial fingerprinting and spectrometric methods ${ }^{95}$. However, we are still lacking the integrative databases and computational tools that would enable us to identify significant relationships between the detailed molecular composition of soil organic carbon, expressions of microbial and plant activities, and soil environmental conditions. The development of international libraries and high-performance computational databases for molecular SOM research will be necessary to take advantage of new molecular tools and create synthesis across analytical platforms.

\section{Mechanisms in global ecosystem models}

The current soil models embedded in Earth system models are structured around 3-5 pools of organic substrates, with transformation rates modified by empirical correlations to soil temperature and water content, and with clay content as a proxy for mineral stabilization of organic matter ${ }^{75-78}$. These models have proven extremely useful, but in the case of long-term feedbacks to climate, a more realistic representation of what governs organic-matter stability will be needed to more accurately inform predictions and policies. Table 1 characterizes what the most widely used ecosystem models do, relative to the insights described above, and gives our recommendations for how to incorporate recent advances into models. Many of the recommendations in Table 1 are what we consider 'low-hanging fruit': that is, modifications that could be made in existing model frameworks, with existing knowledge and data, and that should make significant improvements.

Specifically, we suggest changes along three 'axes'. First, decay of organic matter is a biological process and should be treated as such in models. For example, changes in below-ground carbon allocation or in nutrient availability may alter microbial community composition and activity, which in turn will alter the rate of degradation and the types of organic matter that are degraded. Rhizospheric inputs of energy-rich substrates may aid in, or prime, the decomposition of compounds that would otherwise be selectively avoided by microorganisms ${ }^{49}$. This breadth of biological influence is not currently accounted for.

Second, evidence demonstrating the relatively fast degradation of char and lignin implies that all substrates are degradable within a suitable environment. Likewise, molecules that chemically resemble one another can exhibit very different residence times, depending on whether or not they are protected from decay. The way forward for global land models is to change their organizing principle from carbon pools with intrinsic decomposition rates (based on correlations with texture or litter quality, and modified by climate and land-use type) to more mechanistic representations of the stabilization processes that actually govern carbon dynamics and therefore the strength of climate feedbacks.

Third, representing fine-scale processes and heterogeneity at the large scale of global models is a major challenge for the field. Box models, which have been the basis for modelling soil carbon, assume a mean behaviour at a specific spatial scale. Frequently, however, the distributions of substrates, microorganisms and environmental conditions are highly skewed. For example, a soil that is on average at optimal soil water content for microbial activity will contain pockets that are too wet (such as inside aggregates) as well as too dry (such as inside hydrophobic microsites). At the landscape scale, a small inundated area exerts a disproportionate effect on average methane emissions of a global model grid cell. Because decomposition responds nonlinearly to its drivers, average environmental conditions are imprecise predictors of the perturbed system, and models that can represent this spatial dimension, from the micro-site to the profile to the landscape, are likely to fare better than current models. Advances in numerical methods make possible more mechanistic treatments of transport, taxa-specific microbial requirements and other threedimensional phenomena ${ }^{96}$.

Moving forward requires identifying which parameters are critical, developing practical representations of these processes and parameters, and testing predictions of SOM dynamics against observations at the relevant scales ('ground-truthing'). One reason that models have not incorporated recent scientific developments is the lack of appropriate data for parameterization and testing. The advanced analytical techniques and long-term experiments called 


\begin{tabular}{ll} 
Insight & Relevant model properties \\
\hline 1. Molecular structure & $\begin{array}{l}\text { Decay rate of all pools keyed to substrate (or texture in } \\
\text { CENTURY-type models*) and modified by moisture and } \\
\text { temperature as constant } Q_{10} \text { above } 0^{\circ} \mathrm{C} .\end{array}$ \\
2. Humic substances & $\begin{array}{l}\text { Have a cascade of increasing intrinsic recalcitrance due to } \\
\text { decomposition and synthesis. }\end{array}$ \\
3. Fire-derived carton & $\begin{array}{l}\text { Do not include fire-residues as inputs or SOM. Do not } \\
\text { represent decay of analogous substrates. }\end{array}$ \\
4. Roots & $\begin{array}{l}\text { Parameterize litter quality with leaf/needle chemistry. Have } \\
\text { simplified root and dissolved organic carbon inputs. }\end{array}$ \\
5. Physical heterogeneity & $\begin{array}{l}\text { Lack physical processes, such as aggregation (some have } \\
\text { tillage factor), spatial heterogeneity, or processes that would } \\
\text { produce priming effect } \dagger .\end{array}$ \\
No change in processes or rate constants with depth of soil \\
No carbon input. Site-level tuning required to reproduce long \\
turnover times. \\
Lack processes governing permafrost soil carbon cycling. \\
Lack fully coupled methane biogeochemistry.
\end{tabular}

8. Soil micro-organisms Treat microbial biomass as pool of active carbon. Lack effects of microbial community or enzymes on rates and decomposition products.
Recommendations

Model decay rate as function of substrate properties and positions in microenvironment, microbial activity, and soil conditions including $\mathrm{pH}$, temperature and moisture. See 4, 5, 6, 8.

Replace the cascade with cycling of organic matter into and out of microbial biomass. See 1,8 .

Add input pathway for fire-derived carbon. Add aromatic compounds to SOM types.

Use separate characterizations for below-ground and aboveground inputs. See 6.

Non-normal probability distributions, density-dependent terms for organic matter and microbial biomass. Parameters from 3D, fineresolution models.

Representations of mineral associations, root and dissolved organic inputs, and physical disconnections. Explicit depth resolution for decomposition and transport.

Add $\mathrm{O}_{2}$ limitation and freezing effects on $\mathrm{CO}_{2}$ and $\mathrm{CH}_{4}$ production. Develop soil columns to represent inundation, permafrost thaw and thermokarst.

Create and model microbial functional types, analogous to plant functional types. Introduce full soil nitrogen cycle coupled to carbon cycle.

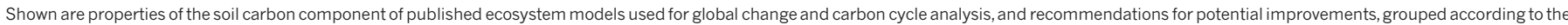

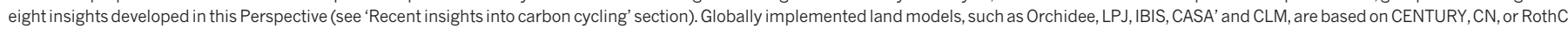
soil models $\mathrm{s}^{75-78}$.

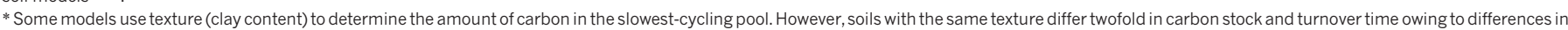
mineralogy, for example ${ }^{99}$. One improvement would be to replace texture with reactive iron and aluminium or mineral surface charge density, estimated globally from a pedotransfer function.

$\dagger$ Priming effect means that carbon input rate has positive effect on decomposition rate.

for above are vital to fill this gap. In addition, more effort is needed both by modellers and empirical scientists to facilitate model evaluation. For example, the ${ }^{14} \mathrm{C}$ content of respired $\mathrm{CO}_{2}$ or leached dissolved organic carbon is a powerful constraint on underlying mechanisms of changes in stocks. In addition, ${ }^{14} \mathrm{C}$ 'clocks' the time carbon has spent in the ecosystem, and is the only way to quantify carbon residence time in undisturbed systems. Yet most ecosystem models lack a ${ }^{14} \mathrm{C}$ tracer that would allow it to be used for testing. Clearly, a comprehensive database of ${ }^{14} \mathrm{C}$ measurements is needed.

\section{Join forces and connect research communities}

The cycling of organic matter is the subject of many different disciplines-from marine chemistry ${ }^{32,97}$ to low-temperature geology to archaeology ${ }^{9}$. Even within SOM research, there have been at least two separate and disconnected directions of research ${ }^{98}$. There are those studying litter decomposition, with a focus on the biotic breakdown of plant inputs, often in forest organic litter layers or agricultural systems. On the other hand, there are those focused on organo-mineral interactions in the mineral soil ${ }^{98}$. Other examples of separated research approaches include agronomic versus ecological questions, aquatic versus terrestrial environments, and laboratory versus field-based experiments. Cross-fertilization is especially needed between empirical scientists and modellers in the context of global change. Insights into mechanisms and observational data will improve predictions, and, in return, the needs of models will motivate useful experiments.

More generally, though, the major advances in our understanding of soils will come from research grounded in the theory of many disciplines and in the practice of many approaches. The future research agenda for soils will integrate many different fields and have broader goals than it might have had in the past, with longer time horizons, wider spatial coverage, and an imperative to connect carbon, water and nutrient cycles, so as to understand the soil-plant system as a crucial part of our biosphere.

1. Fischlin, A. etal. in Climate Change 2007: Impacts, Adaptation and Vulnerability (eds Parry, M. L., Canziani, O. F., Palutikof, J. P., van der Linden, P. J. \& Hanson, C. E.) 211-272 (Cambridge Univ. Press, 2007).

2. Friedlingstein, P. et al. Climate-carbon cycle feedback analysis: results from the $C^{4}$ MIP model intercomparison. J. Clim. 19, 3337-3353 (2006)

A systematic comparison of model predictions of soil carbon response to climate change.
3. von Lützow, M. \& Kögel-Knabner, I. Temperature sensitivity of soil organic matter decomposition-what do we know? Biol. Fertil. Soils 46, 1-15 (2009).

A review and outline of research needs about the response of soil organic matter to rising temperatures

4. Kirschbaum, M. U. F. The temperature dependence of organic-matter decomposition - still a topic of debate. Soil Biol. Biochem. 38, 2510-2518(2006).

5. Heimann, M. \& Reichstein, M. Terrestrial ecosystem carbon dynamics and climate feedbacks. Nature 451, 289-292 (2008).

6. Trumbore, S. E. \& Czimczik, C. I. An uncertain future for soil carbon. Science 321, 1455-1456 (2008).

7. Sollins, P., Homann, P. \& Caldwell, B. A. Stabilization and destabilization of soil organic matter: mechanisms and controls. Geoderma 74, 65-105 (1996). Described mechanisms of SOM stabilization involving environmental controls.

8. Hedges, J. I. et al. The molecularly-uncharacterized component of nonliving organic matter in natural environments. Org. Geochem. 31, 945-958 (2000). Formulated the fundamental question of why, when organic matter is thermodynamically unstable, does it persist in soils, sometimes for thousands of years?

9. Hedges, J. I. \& Oades, J. M. Comparative organic geochemistries of soils and sediments. Org. Geochem. 27, 319-361 (1997).

10. Totsche, K. U. et al. Biogeochemical interfaces in soil: the interdisciplinary challenge for soil science. J. Plant Nutr. Soil Sci. 173, 88-99 (2010).

11. Oades, J. M. The retention of organic matter in soils. Biogeochemistry $\mathbf{5}, \mathbf{3 5 - 7 0}$ (1988).

12. Marschner, B. et al. How relevant is recalcitrance for the stabilization of organic matter in soils? J. Plant Nutr. Soil Sci. 171, 91-110 (2008).

13. Kleber, M. \& Johnson, M. G. Advances in understanding the molecular structure of soil organic matter: implications for interactions in the environment. Adv. Agron. 106, 77-142 (2010).

14. Melillo, J. M., Aber, J. D. \& Muratore, J. F. Nitrogen and lignin control of hardwood leaf litter decomposition dynamics. Ecology 63, 621-626 (1982).

15. Amelung, W., Brodowski, S., Sandhage-Hofmann, A. \& Bol, R. Combining biomarker with stable isotope analysis for assessing the transformation and turnover of soil organic matter. Adv. Agron. 100, 155-250 (2008).

A review including a compilation of the surprisingly rapid and overlapping turnover times of individual molecular compounds previously suspected to have 'slow' turnover.

16. Knorr, M., Frey, S. D. \& Curtis, P. S. Nitrogen additions and litter decomposition: a meta-analysis. Ecology 86, 3252-3257 (2005).

17. Grandy, A. S. \& Neff, J. C. Molecular C dynamics downstream: the biochemical decomposition sequence and its impact on soil organic matter structure and function. Sci. Total Environ. 404, 297-307 (2008).

18. Ekschmitt, K. et al. Soil-carbon preservation through habitat constraints and biological limitations on decomposer activity. J. Plant Nutr. Soil Sci. 171, 27-35 (2008).

19. Stevenson, F. J. Humus Chemistry (Wiley, 1994).

20. Olk, D. C. \& Gregorich, E. G. Overview of the symposium proceedings, "Meaningful pools in determining soil carbon and nitrogen dynamics". Soil Sci. Soc. Am. J. 70, 967-974 (2006).

21. von Lützow, M. et al. Stabilization of organic matter in temperate soils: mechanisms and their relevance under different soil conditions - a review. Eur. J. Soil Sci. 57, 426-445 (2006). 
22. Lehmann, J. et al. Spatial complexity of soil organic matter forms at nanometre scales. Nature Geosci. 1, 238-242 (2008).

23. Sutton, R. \& Sposito, G. Molecular structure in soil humic substances: the new view. Environ. Sci. Technol. 39, 9009-9015 (2005).

24. Haumaier, L. \& Zech, W. Black carbon - possible source of highly aromatic components of soil humic acids. Org. Geochem. 23, 191-196 (1995).

25. Trompowsky, P. M. et al. Characterization of humic like substances obtained by chemical oxidation of eucalyptus charcoal. Org. Geochem. 36, 1480-1489 (2005).

26. Preston, C. M. \& Schmidt, M. W. I. Black (pyrogenic) carbon: a synthesis of current knowledge and uncertainties with special consideration of boreal regions.

Biogeosciences 3, 397-420 (2006).

A summary of the current understanding of the formation, properties and fate of fire-residues in natural ecosystems.

27. Schmidt, M. W. I. \& Noack, A. G. Black carbon in soils and sediments: analysis, distribution, implications, and current challenges. Glob. Biogeochem. Cycles 14 777-794 (2000).

28. Cohen-Ofri, I., Weiner, L., Boaretto, E., Mintz, G. \& Weiner, S. Modern and fossil charcoal: aspects of structure and diagenesis. J. Archaeol. Sci. 33, 428-439 (2006).

29. Hammes, K., Torn, M. S., Lapenas, A. G. \& Schmidt, M. W. I. Centennial black carbon turnover observed in a Russian steppe soil. Biogeosciences 5, 1339-1350 (2008).

30. Major, J., Lehmann, J., Rondon, M. \& Goodale, C. Fate of soil-applied black carbon: downward migration, leaching and soil respiration. Glob. Change Biol. 16, 1366-1379 (2010)

31. Kim, S., Kaplan, L. A., Benner, R. \& Hatcher, P. G. Hydrogen-deficient molecules in natural riverine water samples - evidence for the existence of black carbon in DOM. Mar. Chem. 92, 225-234 (2004).

32. Dittmar, T. \& Paeng, J. A heat-induced molecular signature in marine dissolved organic matter. Nature Geosci. 2, 175-179 (2009).

33. Ziolkowski, L. A. \& Druffel, E. R. M. Aged black carbon identified in marine dissolved organic carbon. Geophys. Res. Lett. 37, L16601 (2010)

34. Nguyen, B. T., Lehmann, J., Hockaday, W. C., Joseph, S. \& Masiello, C. A. Temperature sensitivity of black carbon decomposition and oxidation. Environ. Sci. Technol. 44, 3324-3331 (2010).

35. Keiluweit, M., Nico, P. S., Johnson, M. G. \& Kleber, M. Dynamic molecular structure of plant biomass-derived black carbon (biochar). Environ. Sci. Technol. 44, 1247-1253 (2010)

36. Liang, B. et al. Stability of biomass-derived black carbon in soils. Geochim. Cosmochim. Acta 72, 6069-6078 (2008).

37. Cheng, C. H. \& Lehmann, J. Ageing of black carbon along a temperature gradient. Chemosphere 75, 1021-1027 (2009).

38. Lehmann, J. et al. Australian climate-carbon cycle feedback reduced by soil black carbon. Nature Geosci. 1, 832-835 (2008).

39. Brodowski, S., John, B., Flessa, H. \& Amelung, W. Aggregate-occluded black carbon in soil. Eur. J. Soil Sci. 57, 539-546 (2006)

40. Rasse, D. P., Rumpel, C. \& Dignac, M. F. Is soil carbon mostly root carbon? Mechanisms for a specific stabilisation. Plant Soil 269, 341-356 (2005).

41. Kong, A. Y. Y. \& Six, J. Tracing root vs. residue carbon into soils from conventional and alternative cropping systems. Soil Sci. Soc. Am. J. 74, 1201-1210 (2010).

42. Balesdent, J. \& Balabane, M. Major contribution of roots to soil carbon storage inferred from maize cultivated soils. Soil Biol. Biochem. 28, 1261-1263 (1996).

43. Mendez-Millan, M., Dignac, M. F., Rumpel, C., Rasse, D. P. \& Derenne, S. Molecular dynamics of shoot vs. root biomarkers in an agricultural soil estimated by natural abundance ${ }^{13} \mathrm{C}$ labelling. Soil Biol. Biochem. 42, 169-177 (2010).

44. Kramer, C. et al. Recent (4 year old) leaf litter is not a major source of microbial carbon in a temperate forest mineral soil. Soil Biol. Biochem. 42, 1028-1037 (2010).

45. Bird, J. A., Kleber, M. \& Torn, M. S. ${ }^{13} \mathrm{C}$ and ${ }^{15} \mathrm{~N}$ stabilization dynamics in soil organic matter fractions during needle and fine root decomposition. Org. Geochem. 39, 465-477 (2008).

46. Bird, J. A. \& Torn, M. S. Fine roots vs. needles: A comparison of ${ }^{13} \mathrm{C}$ and ${ }^{15} \mathrm{~N}$ dynamics in a ponderosa pine forest soil. Biogeochemistry 79, 361-382 (2006).

47. Godbold, D. L. et al. Mycorrhizal hyphal turnover as a dominant process for carbon input into soil organic matter. Plant Soil 281, 15-24 (2006).

48. Fontaine, S. et al. Stability of organic carbon in deep soil layers controlled by fresh carbon supply. Nature 450, 277-280 (2007).

49. Kuzyakov, Y. Priming effects: interactions between living and dead organic matter. Soil Biol. Biochem. 42, 1363-1371 (2010)

50. Ågren, G. I., Bosatta, E. \& Magill, A. H. Combining theory and experiment to understand effects of inorganic nitrogen on litter decomposition. Oecologia 128 94-98 (2001).

51. Janssens, I. A. et al. Reduction of forest soil respiration in response to nitrogen deposition. Nature Geosci. 3, 315-322 (2010).

52. Chabbi, A., Kogel-Knabner, I. \& Rumpel, C. Stabilised carbon in subsoil horizons is located in spatially distinct parts of the soil profile. Soil Biol. Biochem. 41, 256-261 (2009).

53. Jobbágy, E. G. \& Jackson, R. B. The vertical distribution of soil organic carbon and its relation to climate and vegetation. Ecol. Appl. 10, 423-436 (2000).

54. Trumbore, S. E., Davidson, E. A., de Camargo, P. B., Nepstad, D. C. \& Martinelli, L. A. Belowground cycling of carbon in forests and pastures of Eastern Amazonia. Glob. Biogeochem. Cycles 9, 515-528 (1995).

55. Rumpel, C. \& Kögel-Knabner, I. Deep soil organic matter - a key but poorly understood component of terrestrial C cycle. Plant Soil 338, 143-158 (2011). A comprehensive overview of key challenges to quantitative understanding of deep soil carbon.
6. Kalbitz, K., Schwesig, D., Rethemeyer, J. \& Matzner, E. Stabilization of Cissolved organic matter by sorption to the mineral soil. Soil Biol. Biochem. 37, 1319-1331 (2005).

57. Torn, M. S. et al. Organic carbon and carbon isotopes in modern and 100-year-old soil archives of the Russian steppe. Glob. Change Biol. 8, 941-953 (2002).

58. Fierer, N., Allen, A. S., Schimel, J. P. \& Holden, P. A. Controls on microbial $\mathrm{CO}_{2}$ production: a comparison of surface and subsurface soil horizons. Glob. Change Biol. 9, 1322-1332 (2003).

59. Kramer, C. \& Gleixner, G. Soil organic matter in soil depth profiles: distinct carbon preferences of microbial groups during carbon transformation. Soil Biol. Biochem. 40, 425-433 (2008)

60. Tarnocai, C. etal. Soil organic carbon pools in the northern circumpolar permafrost region. Glob. Biogeochem. Cycles 23, GB2023, doi:10.1029/2008GB003327 (2009).

61. Schuur, E. A. G. et al. The effect of permafrost thaw on old carbon release and net carbon exchange from tundra. Nature 459, 556-559 (2009).

62. Schuur, E. A. G. et al. Vulnerability of permafrost carbon to climate change: implications for the global carbon cycle. Bioscience 58, 701-714 (2008).

63. Nowinski, N. S., Taneva, L., Trumbore, S. E. \& Welker, J. M. Decomposition of old organic matter as a result of deeper active layers in a snow depth manipulation experiment. Oecologia 163, 785-792 (2010).

64. Mack, M. C., Schuur, E. A. G., Bret-Harte, M. S., Shaver, G. R. \& Chapin, F. S. Ecosystem carbon storage in arctic tundra reduced by long-term nutrient fertilization. Nature 431, 440-443 (2004).

65. Nowinski, N. S., Trumbore, S. E., Schuur, E. A. G., Mack, M. C. \& Shaver, G. R. Nutrient addition prompts rapid destabilization of organic matter in an arctic tundra ecosystem. Ecosystems 11, 16-25 (2008).

66. Striegl, R. G., Aiken, G. R., Dornblaser, M. M., Raymond, P. A. \& Wickland, K. P. A decrease in discharge-normalized DOC export by the Yukon River during summer through autumn. Geophys. Res. Lett. 32, L21413, doi:10.1029/2005GL024413 (2005).

67. Kawahigashi, M., Kaiser, K., Rodionov, A. \& Guggenberger, G. Sorption of dissolved organic matter by mineral soils of the Siberian forest tundra. Glob. Change Biol. 12, 1868-1877 (2006).

68. Raes, J. \& Bork, P. Molecular eco-systems biology: towards an understanding of community function. Nature Rev. Microbiol. 6, 693-699 (2008).

69. Morales, S. E. \& Holben, W. E. Linking bacterial identities and ecosystem processes: can 'omic' analyses be more than the sum of their parts? FEMS Microbiol. Ecol. 75, 2-16 (2011).

70. Kögel-Knabner, I. The macromolecular organic composition of plant and microbial residues as inputs to soil organic matter. Soil Biol. Biochem. 34, 139-162 (2002).

71. McGuire, K. L. \& Treseder, K. K. Microbial communities and their relevance for ecosystem models: decomposition as a case study. Soil Biol. Biochem. $\mathbf{4 2 ,}$ 529-535 (2010)

72. von Mering, C. et al. Quantitative phylogenetic assessment of microbial communities in diverse environments. Science 315, 1126-1130 (2007).

73. Kleber, M. What is recalcitrant soil organic matter? Environ. Chem. 7, 320-332 (2010).

74. Manzoni, S. \& Porporato, A. Soil carbon and nitrogen mineralization: theory and models across scales. Soil Biol. Biochem. 41, 1355-1379 (2009).

75. Kucharik, C. J.etal. Measurements and modeling of carbon and nitrogen cycling in agroecosystems of southern Wisconsin: potential for SOC sequestration during the next 50 years. Ecosystems 4, 237-258 (2001).

76. Jenkinson, D. S. The turnover of organic carbon and nitrogen in soil. Phil. Trans. R. Soc. Lond. 329, 361-368 (1990)

77. Parton, W. J., Ojima, D. S., Cole, C. V. \& Schimel, D. S. in Quantitative Modeling of Soil Forming Processes (eds Bryant, R. B. \& Arnold, R. W.) 147-167 (Special Publication, Soil Science Society of America, 1994).

78. Thornton, P. E. \& Rosenbloom, N. A. Ecosystem model spin-up: estimating steady state conditions in a coupled terrestrial carbon and nitrogen cycle model. Ecol. Model. 189, 25-48 (2005).

79. Khvorostyanov, D. V., Krinner, G., Ciais, P., Heimann, M. \& Zimov, S. A. Vulnerability of permafrost carbon to global warming. Part I: model description and role of heat generated by organic matter decomposition. Tellus B 60, 250-264 (2008).

80. Arrhenius, S. Über die Reaktionsgeschwindigkeit bei der Inversion von Rohrzucker durch Säuren. Z. Phys. Chem. 4, 226-248 (1889).

81. Davidson, E. A. \& Janssens, I. A. Temperature sensitivity of soil carbon decomposition and feedbacks to climate change. Nature 440, 165-173 (2006).

82. Knorr, W., Prentice, I. C., House, J. I. \& Holland, E. A. Long-term sensitivity of soil carbon turnover to warming. Nature 433, 298-301 (2005).

83. Kirschbaum, M. U. F. The temperature dependence of organic matter decomposition: seasonal temperature variations turn a sharp short-term temperature response into a more moderate annually averaged response. Glob. Change Biol. 16, 2117-2129 (2010).

84. Fang, C., Smith, P., Moncrieff, J. B. \& Smith, J. U. Similar response of labile and resistant soil organic matter pools to changes in temperature. Nature $\mathbf{4 3 3}, 57-59$ (2005).

85. Craine, J. M., Fierer, N. \& McLauchlan, K. K. Widespread coupling between the rate and temperature sensitivity of organic matter decay. Nature Geosci. 3, 854-857 (2010).

86. Lorenz, K., Lal, R., Preston, C. M. \& Nierop, K. G. J. Strengthening the soil organic carbon pool by increasing contributions from recalcitrant aliphatic bio(macro)molecules. Geoderma 142, 1-10 (2007).

87. Thevenot, M., Dignac, M. F. \& Rumpel, C. Fate of lignins in soils: a review. Soil Biol. Biochem. 42, 1200-1211 (2010).

88. Lehmann, J. A handful of carbon. Nature 447, 143-144 (2007). 
89. Sachs, J. et al. Monitoring the world's agriculture. Nature 466, 558-560 (2010).

90. Richter, D. D., Hofmockel, M., Callaham, M. A., Powlson, D. S. \& Smith, P. Long-term soil experiments: keys to managing Earth's rapidly changing ecosystems. Soil Sci. Soc. Am. J. 71, 266-279 (2007)

91. Amundson, R. \& Jenny, H. The place of humans in the state factor theory of ecosystems and their soils. Soil Sci. 151, 99-109 (1991).

92. Amstalden van Hove, E. R., Smith, D. F. \& Heeren, R. M. A. A concise review of mass spectrometry imaging. J. Chromatogr. A 1217, 3946-3954 (2010).

93. Herrmann, A. M. et al. Nano-scale secondary ion mass spectrometry - a new analytical tool in biogeochemistry and soil ecology: A review article. Soil Biol. Biochem. 39, 1835-1850 (2007).

94. Ranjard, L. et al. Biogeography of soil microbial communities: a review and a description of the ongoing French national initiative. Agron. Sustain. Dev. 30, 359-365 (2010).

95. Pascault, N. et al. In situ dynamics of microbial communities during decomposition of wheat, rape and alfalfa residues. Microb. Ecol. 60, 816-828 (2010).

96. Xu, T. F. Incorporating aqueous reaction kinetics and biodegradation into TOUGHREACT: applying a multiregion model to hydrobiogeochemical transport of denitrification and sulfate reduction. Vadose Zone J. 7, 305-315 (2008).

97. Jiao, N. et al. Microbial production of recalcitrant dissolved organic matter: long-term carbon storage in the global ocean. Nature Rev. Microbiol. 8, 593-599 (2010).
98. Sollins, P., Swanston, C. \& Kramer, M. Stabilization and destabilization of soil organic matter - a new focus. Biogeochemistry 85, 1-7 (2007).

99. Torn, M. S., Trumbore, S. E., Chadwick, O. A., Vitousek, P. M. \& Hendricks, D. M. Mineral control of soil organic carbon storage and turnover. Nature 389, 170-173 (1997).

100. Kelleher, B. P. \& Simpson, A. J. Humic substances in soils: are they really chemically distinct? Environ. Sci. Technol. 40, 4605-4611 (2006).

Acknowledgements The European Science Foundation Network MOLTER sponsored the workshop at which the idea for this Perspective was conceived. Support for M.W.I.S. and M.S.T. was also provided by the US Department of Energy (contract no. DE-AC02-05CH11231).

Author Contributions M.W.I.S. coordinated the MOLTER-sponsored workshop mentioned above; the ideas were developed by all authors. M.W.I.S. and M.S.T. participated actively and equally in the writing of the manuscript and the drafting of the figures. All authors provided input into the drafting and the final version of the manuscript.

Author Information Reprints and permissions information is available at www.nature.com/reprints. The authors declare no competing financial interests. Readers are welcome to comment on the online version of this article at www.nature.com/nature. Correspondence should be addressed to M.W.I.S. (Michael.Schmidt@geo.uzh.ch) or M.S.T. (mstorn@lbl.gov). 


\section{DISCLAIMER}

This document was prepared as an account of work sponsored by the United States Government. While this document is believed to contain correct information, neither the United States Government nor any agency thereof, nor The Regents of the University of California, nor any of their employees, makes any warranty, express or implied, or assumes any legal responsibility for the accuracy, completeness, or usefulness of any information, apparatus, product, or process disclosed, or represents that its use would not infringe privately owned rights. Reference herein to any specific commercial product, process, or service by its trade name, trademark, manufacturer, or otherwise, does not necessarily constitute or imply its endorsement, recommendation, or favoring by the United States Government or any agency thereof, or The Regents of the University of California. The views and opinions of authors expressed herein do not necessarily state or reflect those of the United States Government or any agency thereof or The Regents of the University of California.

Ernest Orlando Lawrence Berkeley National Laboratory is an equal opportunity employer. 